Supporting Information

\title{
Effect of varying the cation ratio within iron molybdate catalysts for the selective oxidation of methanol
}

Matthew P. House, Albert F. Carley, Ricardo Echeverria-Valda, Michael Bowker.

School of Chemistry, Main Building, Cardiff University, Cardiff, CF10 3AT

Figure S1 - CO selectivity as a function of temperature. Symbols as in Figure 4.

Figure S2- $\mathrm{CO}_{2}$ selectivity as a function of temperature. Symbols as in Figure 4.

Figure S3 - Dimethyl ether selectivity as a function of temperature. Symbols as in Fig. 4

Figure S4 - Comparison of selectivity to $\mathrm{CO}_{2}$ of catalysts at varying methanol conversions. Labels as in Figure 4.

Figure S5 - Comparison of selectivity to CO of catalysts at varying methanol conversions. Labels as in Figure 4.

Figure S6 - Desorption of methanol from surfaces saturated with methanol at room temperature. a) $\mathrm{Fe}_{2} \mathrm{O}_{3}$, b) Mo:Fe 0.02:1, c) Mo:Fe 0.05:1 d) Mo:Fe, 0.2:1, e) Mo:Fe, 0.5:1 0.5g, f) Mo:Fe, 0.5:1 0.1g, g) Mo:Fe, 1:1, h) Mo:Fe, 1.5:1, i) Mo:Fe, 2.2:1 and j) $\mathrm{MoO}_{3}$. Figure S7 - Desorption of water from surfaces saturated with methanol at room temperature. Labels as in Supplementary Figure 1. 
Figure S1

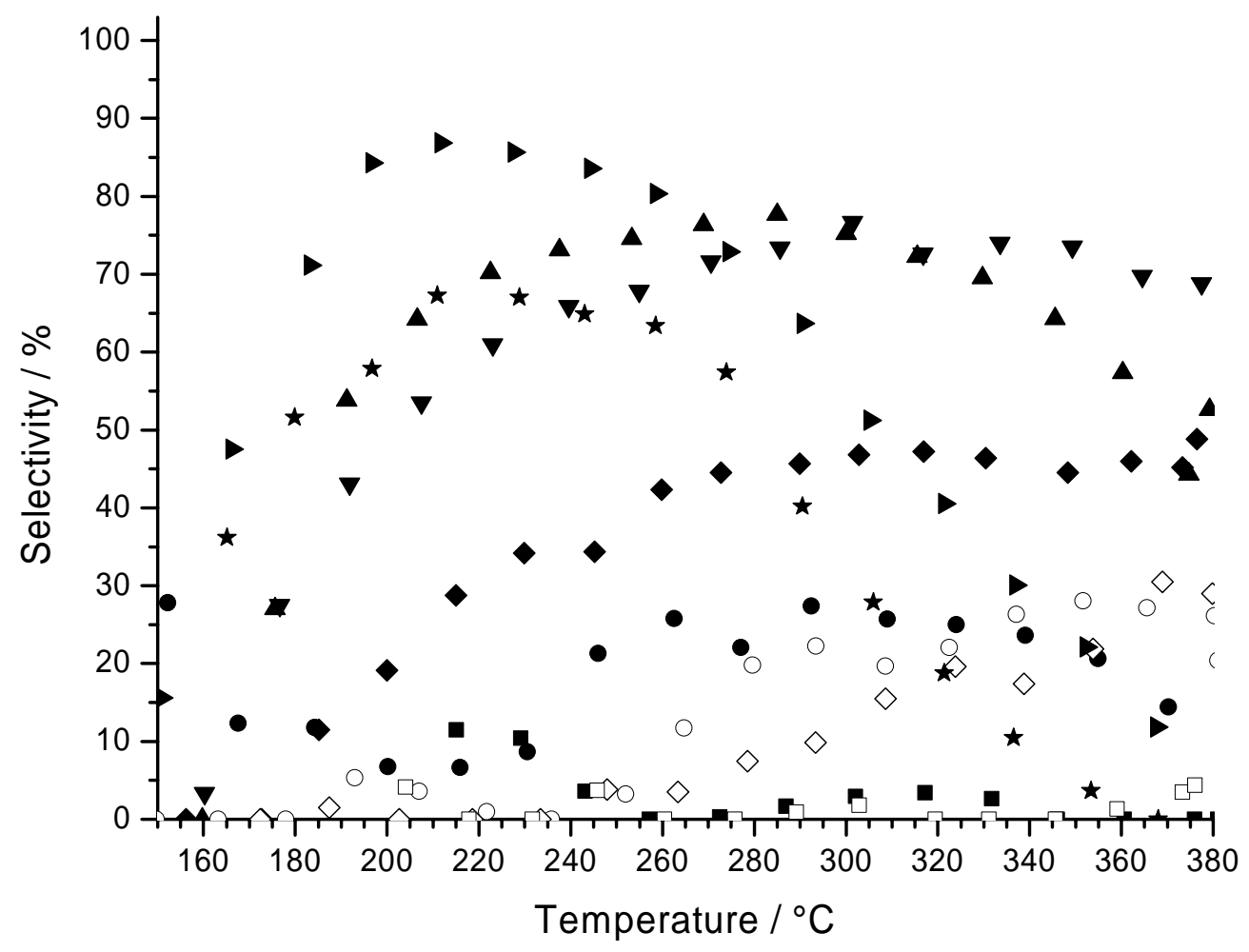

Figure S2 


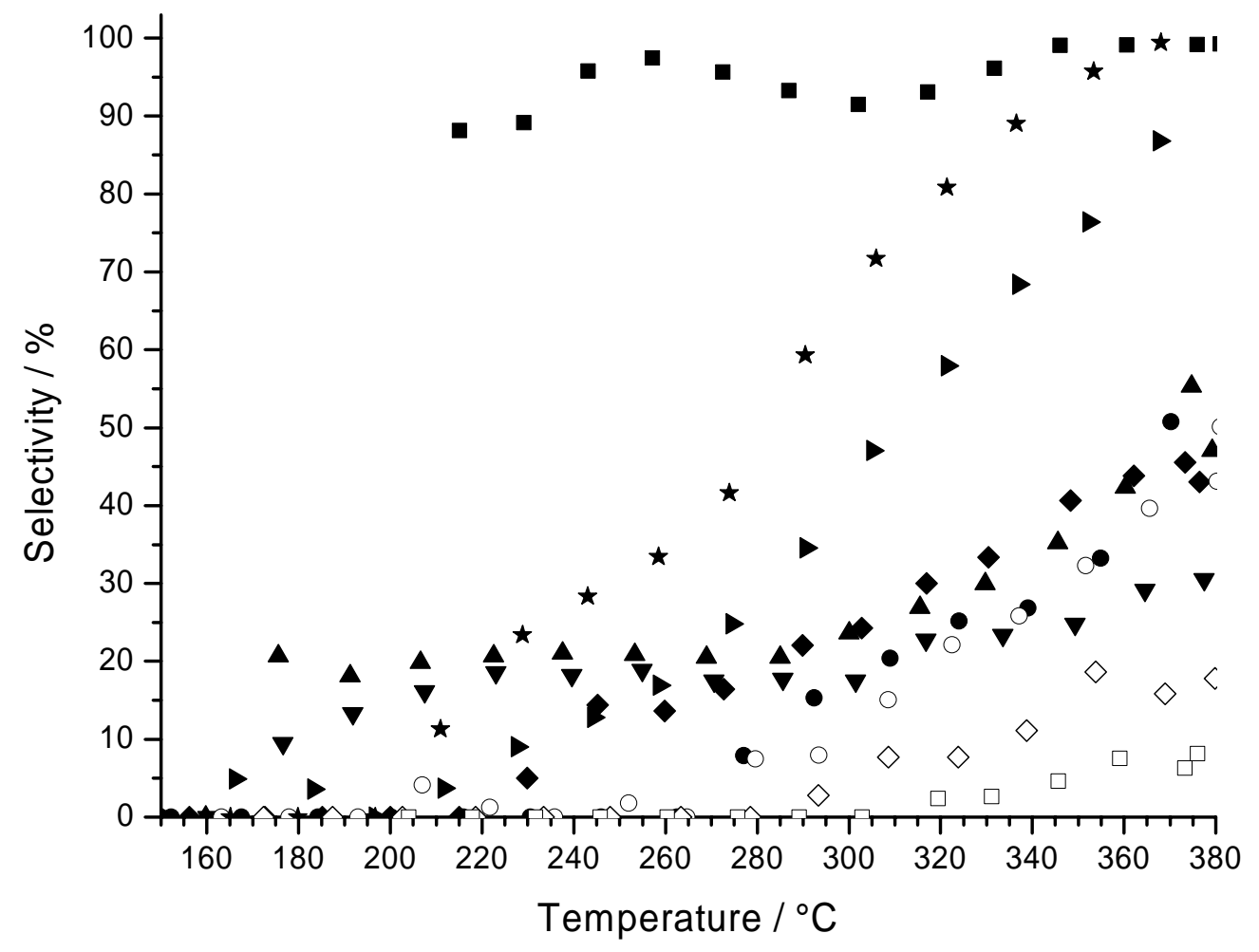

Figure S3

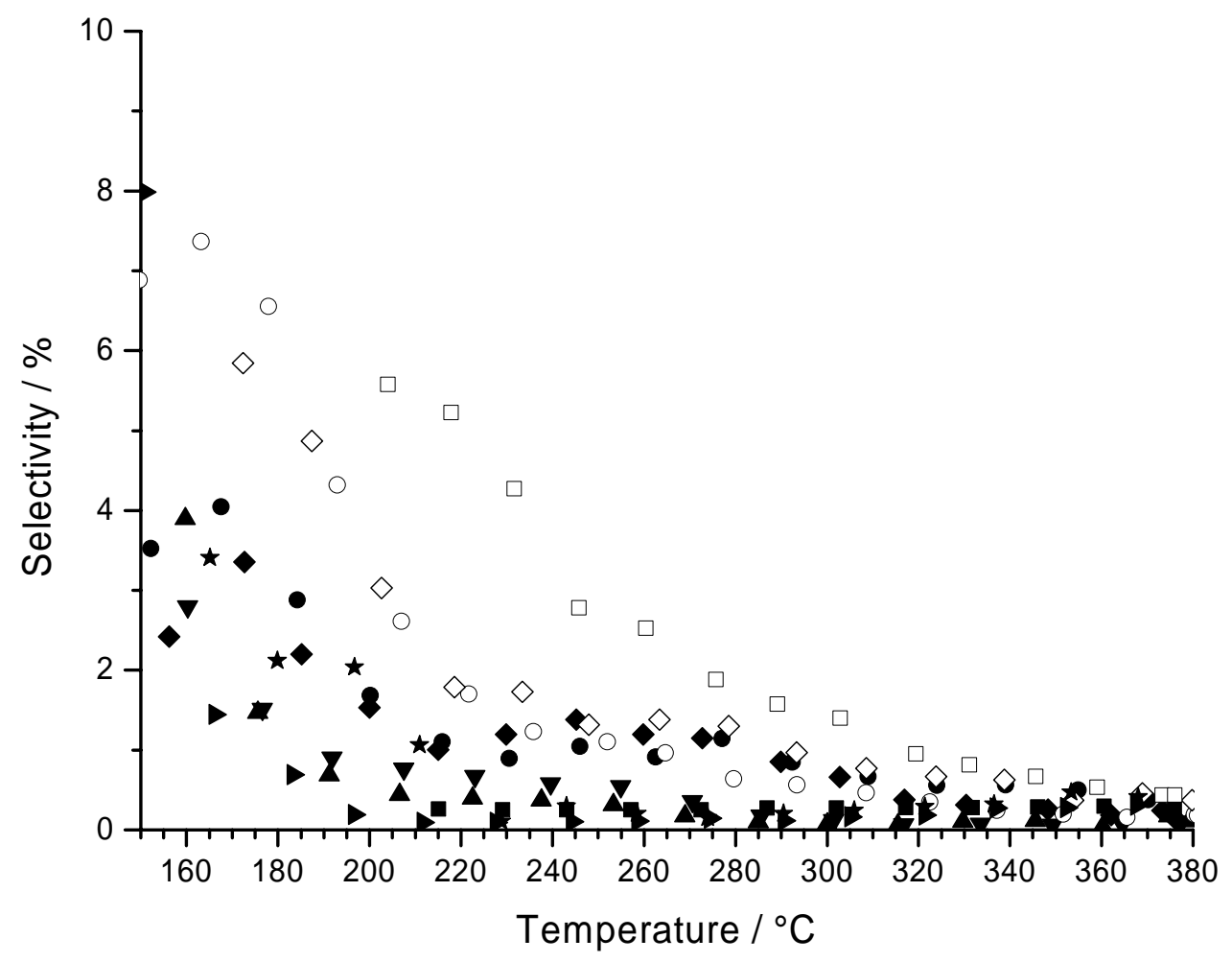


FigureS4

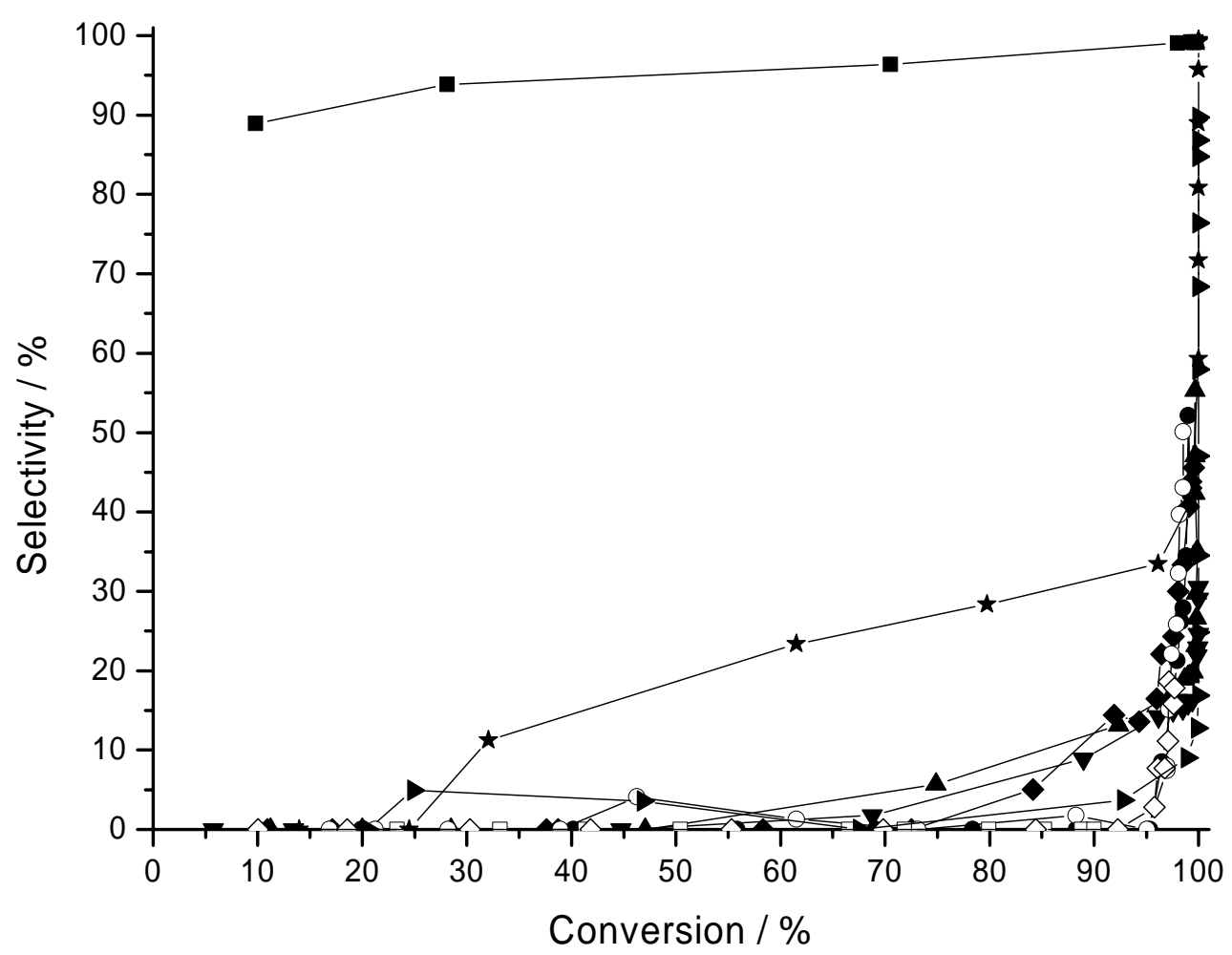

Figure S5 


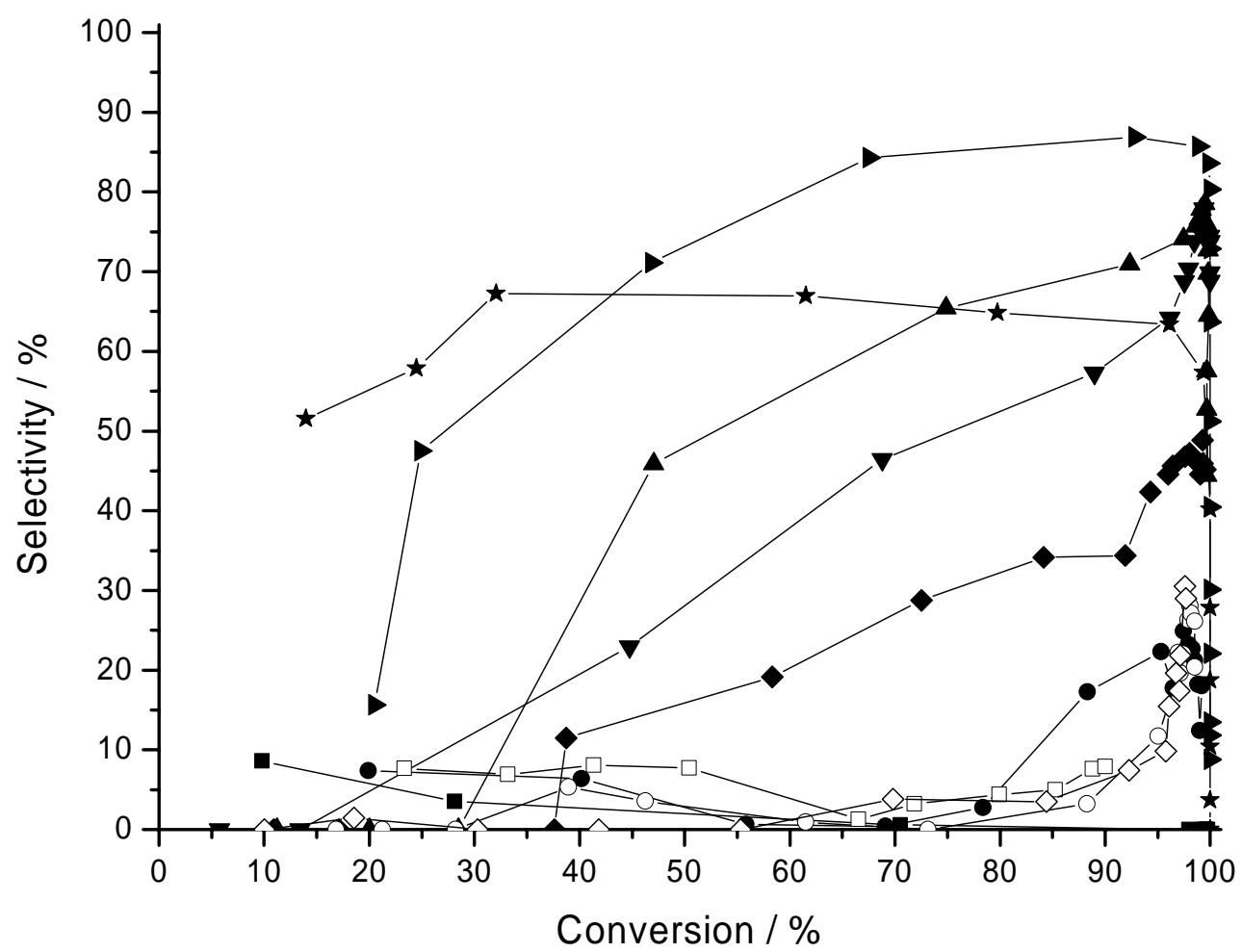

The TPD profiles for molecular methanol desorption (Figure S6) are rather broad and illdefined, with desorption beginning shortly after heating and extending to $\sim 200^{\circ} \mathrm{C}$. This is the most weakly-held material and probably represents molecularly-held methanol. Fig. S2 shows water evolution, which generally has two broad states of evolution, one near room temperature and one at elevated temperature. The latter is generally associated with the desorption of products of methanol decomposition which are shown in figs. 8a $\left(\mathrm{H}_{2} \mathrm{CO}\right)$ and $\mathrm{b}\left(\mathrm{CO}, \mathrm{CO}_{2}\right.$, and $\left.\mathrm{H}_{2}\right)$, and the general trend shown is that this state increases in temperature as the amount of $\mathrm{Fe}$ in the catalyst increases, being at $\sim 180^{\circ} \mathrm{C}$ for molybdenum-rich catalysts, and $\sim 260^{\circ} \mathrm{C}$ for Fe-rich samples. This, in turn, reflects the nature of the intermediates present on the surface, which decompose at $\sim 180^{\circ} \mathrm{C}$ for Morich samples and $\sim 260^{\circ} \mathrm{C}$ for the Fe-rich samples. The product which desorbs at the low temperature end of this range is formaldehyde, always with a reasonably well-defined peak between $175^{\circ} \mathrm{C}$ and $190^{\circ} \mathrm{C}$. 
Figure S6

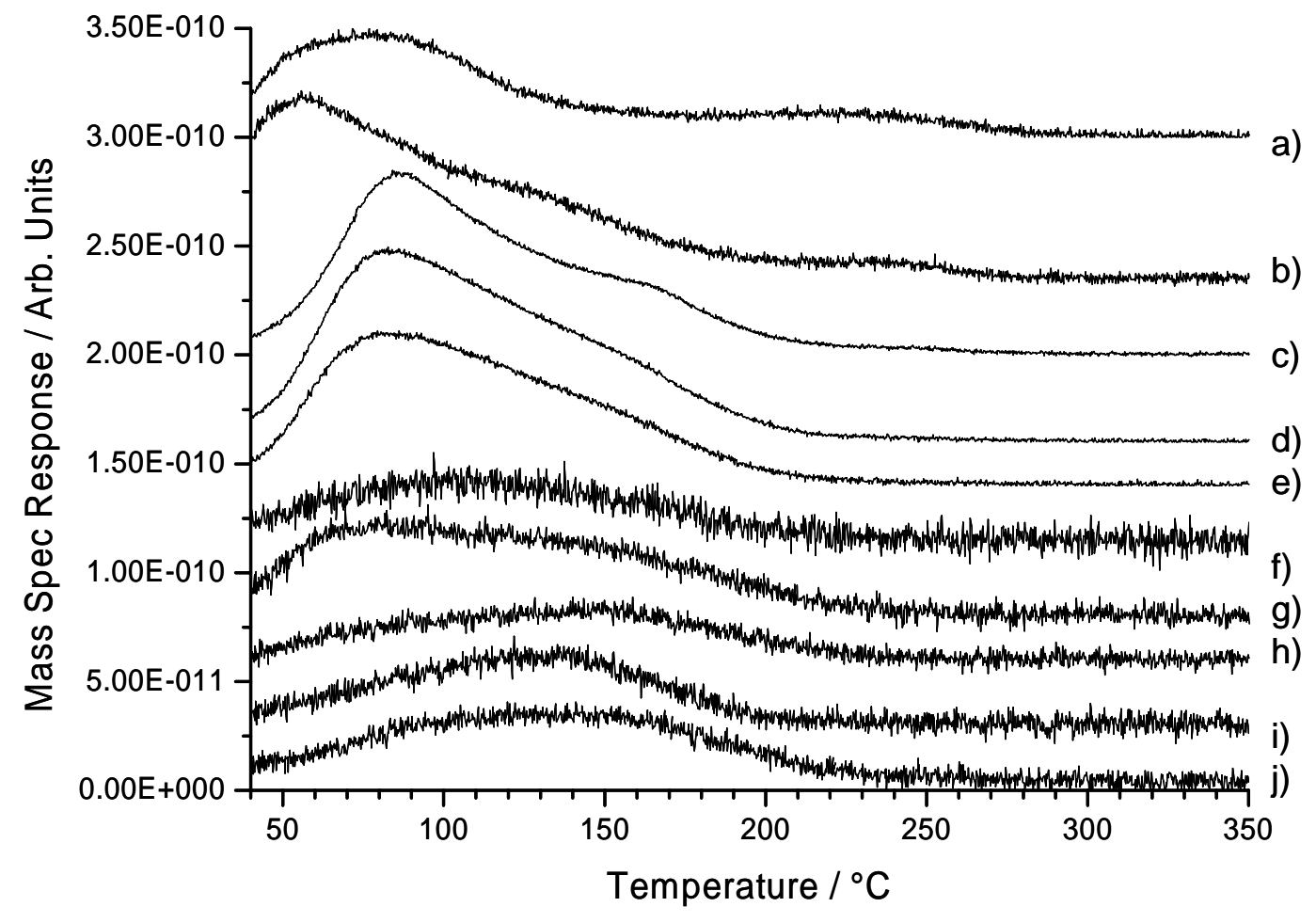

Figure S7 


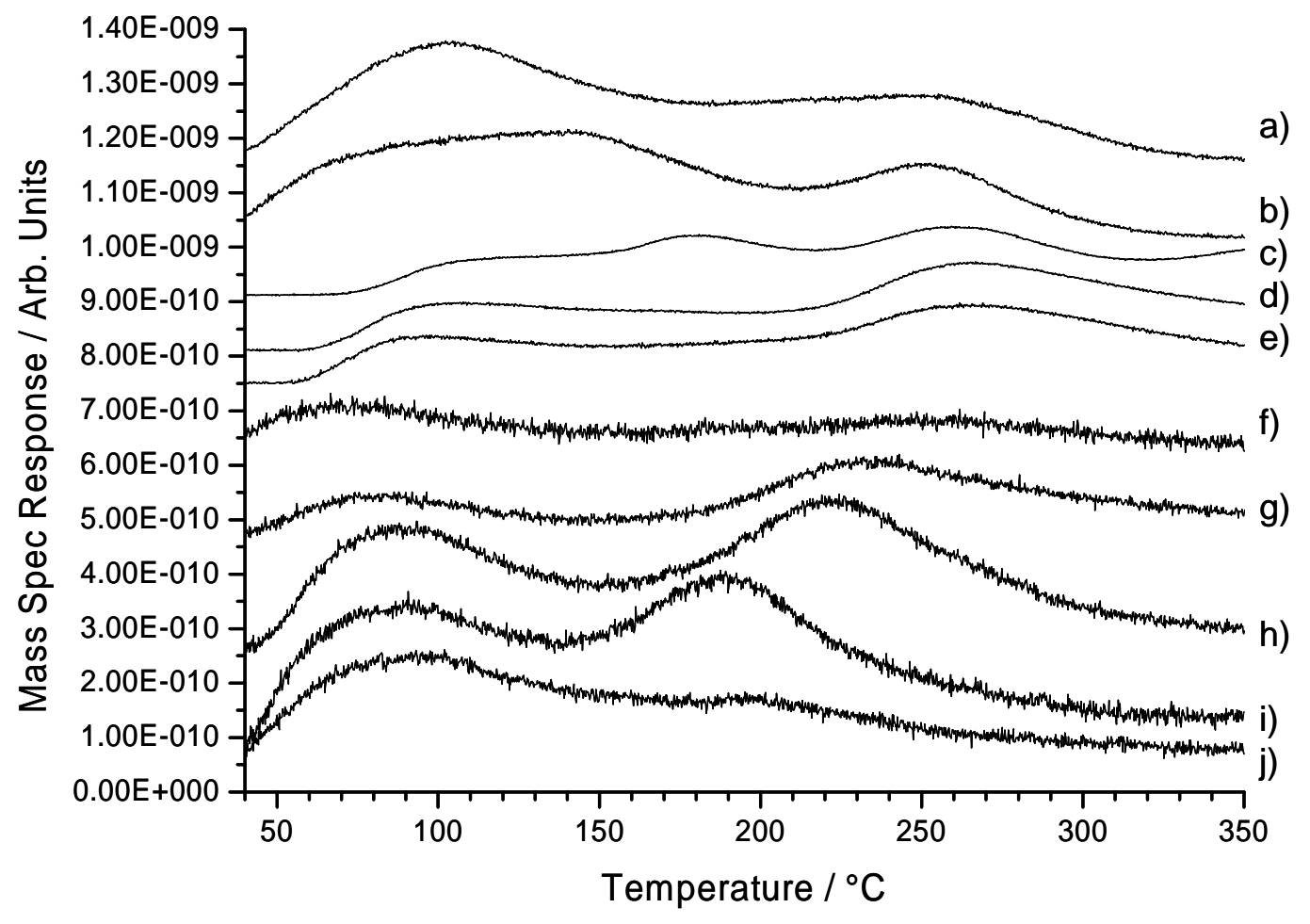

